\title{
A Comparison of the Characteristics of Urban and Rural Bus Transport in Sri Lanka - A Case Study
}

\author{
Tissa U. Liyanage, Pradeepa R. Jayaratne and Amal S. Kumarage
}

\begin{abstract}
The public bus transport systems in most developing countries are not at a satisfactory level especially from the passenger point of view. Overloading at peak hours, waiting and travel time delay during the off peak, anti-social behaviour of bus crews, unacceptable noise levels, inadequate and unacceptable user comfort, lack of user rights, lack of night services and of non profitable routes are few of the major issues in the public bus transport system in Sri Lanka as well. There are a number of reasons for this situation. One of the main reasons is the lack of management of the demand and provision of adequate supply of public bus transport that satisfied both the user and operator simultaneously. Inability to understand the qualitative parameters of the transport supply demanded leads to poor response to this situation by both passengers and their communities as well as policy agencies. These parameters differ contextually. For example the requirements of typical urban passengers differ from those of rural passengers.
\end{abstract}

This paper analyses the results of a case study which compares the inherited problems in a bus transport system under typical urban and rural situations. The user response by interviews, bus loading and travel time surveys, from each of these locations has been analysed to understand and compare the problems in each situation. The analysis also shows a significant difference in supply and demand characteristics of the bus transport system between urban and rural areas in Sri Lanka. The research paper also discusses the need for passenger empowerment as one of the interventions needed to mitigate the present problems in Sri Lanka's public bus transport system.

Keywords: Urban and Rural Bus Transport, Demand and Supply Management, Passenger empowerment

\section{Introduction}

Provision of bus passenger transport is one of the largest industries in Sri Lanka. The total share of inland transportation provided by buses are high as it is more than half of the total passenger transportation demand at present. The market share among State-owned and private owned bus services varies by location and depends on the demand in the area. Apparently, private owners being profit oriented always select profitable routes while the State owned buses are often left to run non profitable routes as a service to the community. There is a significant difference in the fleet capacity and the share of the revenue among the two service providers in Sri Lanka.

According to previous studies, it has been shown that the available bus fleet is in excess of the present demand if it is managed well [5] using scientifically designed time tables [6]. Some of the other reasons for unsatisfactory service due to bad management can be observed as; time schedules not being monitored at terminals, no proper coordination between time tables of private and State owned buses on a route, non availability of rotating time tables for changing the turns between peak and off peak demand, lack of ordinance to safeguard passengers against anti-social activities, and many more. This situation has led to loss of profit to the operators which in turn renders them unable to provide a satisfactory service to the passengers.

These shortcomings are reflected in terms of overloading, delay at start terminal, delay at intermediate stops, unsafe driving, frequent

\footnotetext{
Eng. Tissa U. Liyanage, C. Eng., MIE(Sri Lanka), B.Sc. Eng. (Hons) (Moratuwa), M.Eng., PhD Candidate \& Research Assistant, Department of Civil Engineering, University of Moratuwa, Sri Lanka.

Miss Pradeepa $\boldsymbol{R}$. Jayaratne, M.Sc. Logistics (Wollongong), Adv. Dip (Transport) UK, Dip in Transport (UK), CMILT, Department of Civil Engineering, University of Moratuwa

Eng. (Prof) Amal S. Kumarage, FCILT, B.Sc. Eng. (Hons) (Moratuwa), PhD (Calgary), MIE(Sri Lanka), C.Eng, Professor of Civil Engineering, Head, Department of Transport \& Logistics Management, University of Moratuwa, Sri Lanka and is currently Chairman of the National Transport Commission.
} 
clashes between passengers and bus crew, lack of night services, poor service on non profitable routes, on-road competition between operators, poor standard of buses etc. It is very important to analyse these ill-effects in detail from the passenger point of view for a better understanding of the problem.

This study uses both quantitative and qualitative analysis to compare and discuss results of the analysis.

\section{The Objectives}

The following are the objectives of this research paper.

- The primary objective is to understand various problems faced by bus passengers in Sri Lanka.

- Secondly to compare the effects and significance of such problems between urban and rural passengers.

\section{Bus Passenger Transport in Sri Lanka}

The first bus in Sri Lanka (Then Ceylon) commenced operation around 1907. Since then, buses were operated by private companies till 1951 and then by public companies till the bus was nationalized in 1958. The Ceylon Transport Board (CTB) as a state-owned monopoly undertook the operation and continued untill 1978, when it was decentralized into nine Regional Transport Boards (RTB). Since 1979, the private sector has been allowed to operate on selected routes. In 1985, Private Omnibus Associations (POA) were set up. Since then several reforms were introduced to ensure efficient public bus transport service by CTB as well as private operators, but has not been entirely successful so far[4 ].

Table 1: Sri Lanka Modal Shares (2001)

\begin{tabular}{|l|r|r|}
\hline \multirow{2}{*}{ Mode of Travel } & \multicolumn{2}{|c|}{ Travel Kilometres (Mn) } \\
\cline { 2 - 3 } & \multicolumn{1}{|c|}{ Vehicle } & \multicolumn{1}{c|}{ Passenger } \\
\hline Bus & $966(08 \%)$ & $45,407(68 \%)$ \\
\hline Private Vehicles & $7,861(64 \%)$ & $15,831(24 \%)$ \\
\hline Railways & $11(00 \%)$ & $3,600(5 \%)$ \\
\hline Three Wheelers & $1,548(13 \%)$ & $1,161(2 \%)$ \\
\hline Truck/LandVehicles & $1,813(15 \%)$ & $907(1 \%)$ \\
\hline Water Transport & $3(00 \%)$ & \\
\hline Total & $12,202(100 \%)$ & $66,906(100 \%)$ \\
\hline
\end{tabular}

A summary of the share by different modes of transport in Sri Lanka is given in Table 1. It can be seen that today, $68 \%$ of all motorized passenger kilometres in Sri Lanka are made by bus. This indicates the success of the bus industry in Sri Lanka in terms of coping with the demand even though it continues to lose to the private vehicles since qualitative improvements have not kept pace.

\section{Study Area}

The two areas for the surveys were selected to cover typical urban and rural conditions. Mattegoda housing scheme of Kottawa in the Colombo District and Kudaligama village, off Matugama in the Kalutara District were chosen as urban and rural areas respectively. The two study areas are shown in the Location Map (Figure 1). The socio economic characteristics of the study areas- such as the number of households and population, the transportation characteristics such as number of bus routes severing the area, number of buses and trips per day, were considered in selecting the suitability of the area.

\section{Mattegoda Housing Scheme}

Mattegoda housing scheme is situated approximately $18 \mathrm{~km}$ away from Colombo Fort and to the south east of the city. The housing scheme which is managed by the Homagama Divisional Secretariat is situated within the Homagama Pradeshiya Sabha. The scheme is located is $4.5 \mathrm{~km}$ from the closest at Kottawa which is on the A4 highway, a main arterial road in Sri Lanka. The scheme is partly spread over four Gramaseva Divisions namely, Mattegoda Central A, Mattegoda Central B, Mattegoda East and Mattegoda West.

\section{Kudaligama Rural Area}

The village, Kudaligama belongs to Bulathsinhala Divisional Secretariat situated $14.2 \mathrm{~km}$ away from Matugama town in, the Kalutara District and $72 \mathrm{kms}$ from Colombo. The study was confined to three Gramaseva Niladari Divisions namely Ihala Kudaligama, Pahala Kudaligama and Girikola, The population is approximately 1850 and there are around 750 households in the area. There is a high school in the village. The students either walks to school or common by bus. There is hardly any large industry the area. Agricultural activities such as paddy farming are inherent to the area. Majority of the population is employed at urban centres and commute daily to these towns and some even to Colombo. 


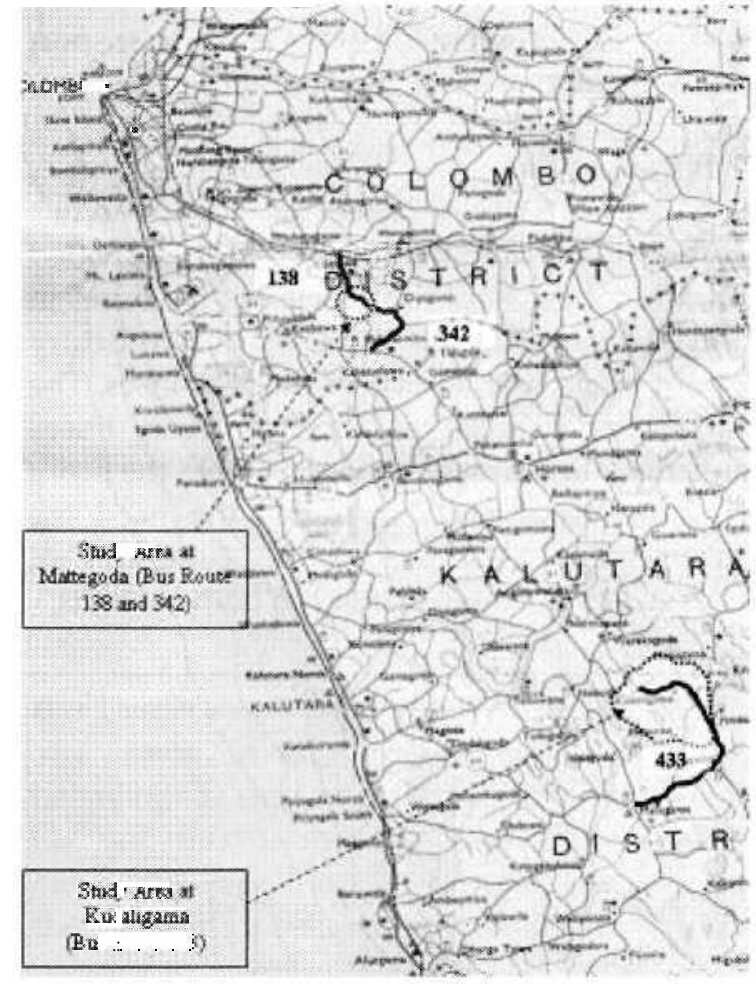

Figure 1: Location Map of the Study Area

\section{Data Collection}

Bus Travel Time Survey and Bus Loading Survey were carried out on two consecutive days for each study. 120 households from in the Mattegoda housing scheme were covered under the household survey which represented over $10 \%$ sample of the total population of the area. Randomly selected sample from Kudaligama rural area was 121 households $(15 \%)$. Since there are several types (B, C \& F type houses) of housing in Mattegoda scheme, equal sample rate was selected from the each type.

Travel Time Surveys and Bus Passenger Loading Surveys were carried out on the Number 138 route and Number 342 route as urban routes in Mattegoda, while the Number 433 bus route was a rural route (Figure 1) in Kudaligama. The selected lengths for above routes were $4.5 \mathrm{~km}, 6.75 \mathrm{~km}$ and $14.2 \mathrm{~km}$ respectively.

\section{Analysis}

This analysis has been carried out based on three important contents: i.e; household interviews, passenger loading data and travel time data. Each item is discussed separately.

\subsection{Analysis of Household Surveys}

Table 1 has been derived based on the responses of the passengers on the quality of bus services available in the two study areas. Those who have indicated it as being excellent or very good have been given an average of 95 points (or marks) while those who indicated 'good' were given an average of 80 points, while those who indicated 'acceptable', were given an average of 55 points, with unacceptable scores fetching 20 points on average. This has been formulated on the basis of points given for general education which are well known among the public. In this case an average of around 40 points is generally known as a 'failure' while between 40 to around 70 may be considered as acceptable, and those higher than 70 would be considered as very good. The percentage responses in each category of service level are tabulated for both urban and rural areas.

According to Table 2 the quality of service with respect to overloading and non-issuing of tickets in urban areas can be termed as failing to satisfy the minimum requirement. On the other hand, the condition of the bus, the bus fare and the frequency of buses (waiting time) are considered as having met with required standard with the other attributes leaving much room for improvement. In rural areas, overloading, condition of buses and bus stops, waiting time attributes need improvements.

Table 2: Percentage Response on Bus Service (Urban and Rural Comparison)

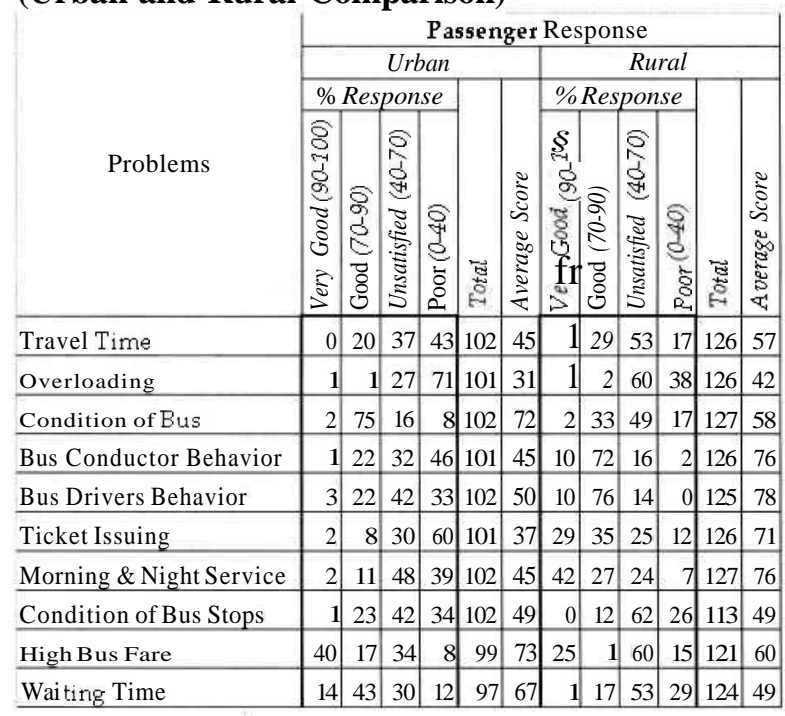

The individual score attained by each service attribute are compared between urban and rural context and discussed using ensuing bar charts given below. 


\section{Travel Time}

The comparison of user response on travel time to complete the one way journey at urban and rural area services are shown in Figure 2. Bus passengers in both areas are unhappy with this attribute. Results show that more than $80 \%$ of urban users and more than $70 \%$ rural users are dissatisfied about the travel time of the journey. Average effect is shown by average score of the response as 45 in urban areas where as this is $\mathbf{5 7}$ in rural areas. This means that urgent attention is required to urban areas even though both situations require improvements.

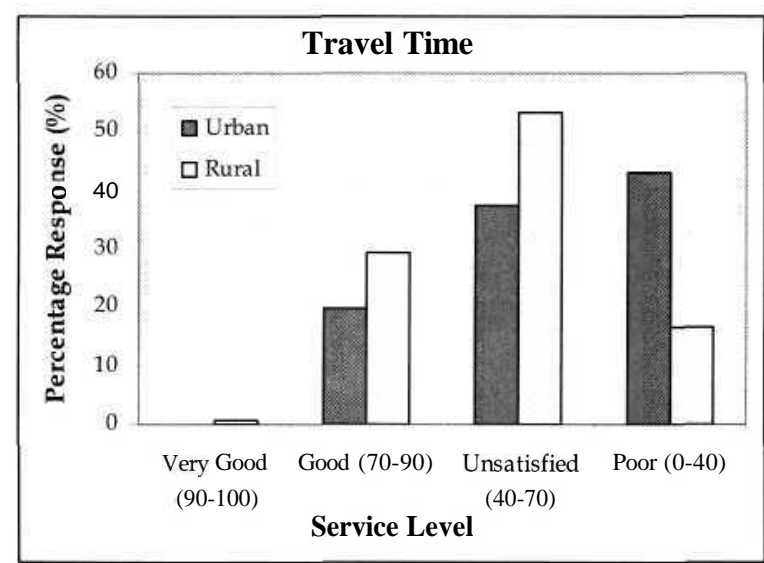

Figure 2: Passenger Response on Travel Time

\section{Overloading}

The response of the passengers on overloading is far worse than the effect of travel time delay. More than $98 \%$ of the passengers appeared to suffer from overloading of the buses (Figure 3).

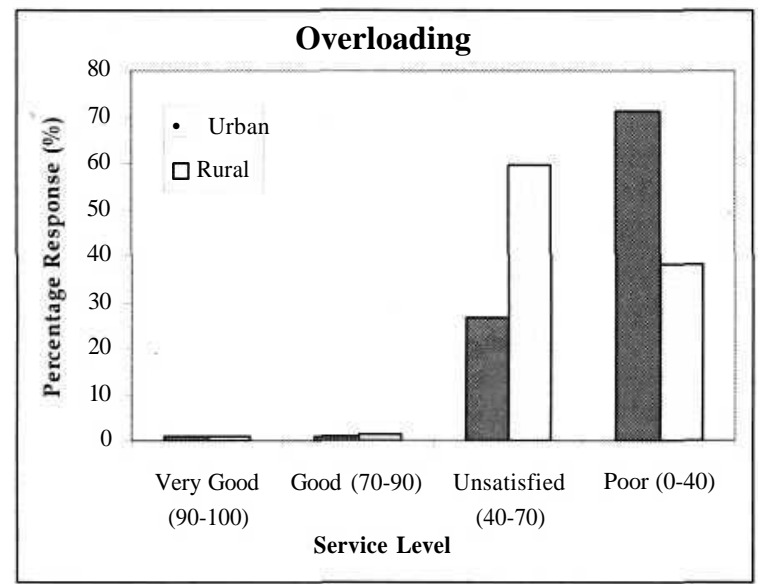

Figure 3: Passenger Response on Overloading

Here too, the worse situation is found in urban services. The average score calculated is 31 . This is the worst average score in this analysis. The corresponding score is 42 for rural services which is also the lowest attribute score for rural services. This shows that overloading is the most severe problem in today's bus transport service from the passenger's point of view.

\section{Condition ofBus}

More than $75 \%$ of responses from the urban bus passengers indicate that they are quite satisfied with the condition of the buses. But the buses in rural services are considered as unsatisfactory or poor by more than $65 \%$ of the responses. The high average score as 72 for urban buses confirms a favourable situation while the score of 58 for rural areas indicates the need for improvement. Generally, the condition of buses seems to be satisfactory in both contexts.

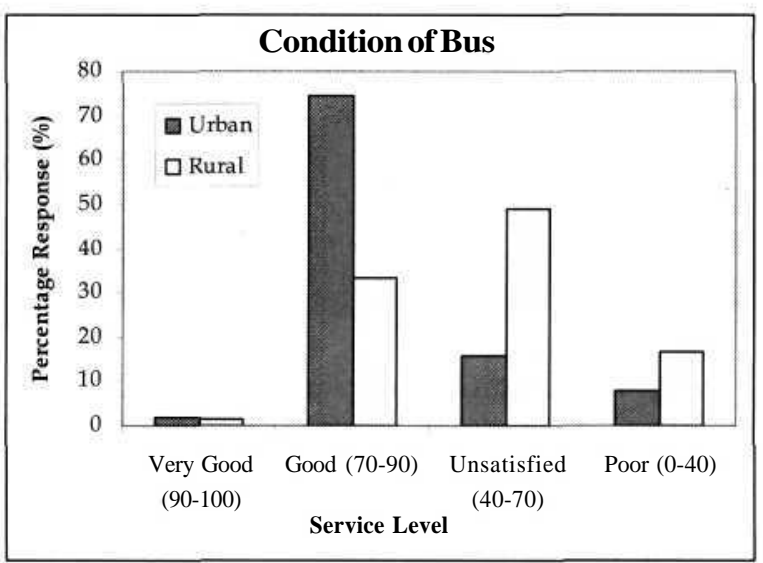

Figure 4: Passenger Response on Bus Condition

\section{Bus Conductor's Behaviour}

The analysis shows there is a significant difference in bus conductor's behaviour from urban to rural (Figure 5) context. Dissatisfaction among urban passengers is high at $77 \%$ while it is low at $18 \%$ among the rural passengers. The average score (45) appears to indicate that urban passengers are not satisfied, while an average score of 76 appears to satisfy most of the rural passengers. The apparent reason could be the close social relationship between conductors and the commuters who are generally known to each other in a rural context but it is not so in urban areas. Problems such as changing of conductors frequently, competition between buses, difference between supply and demand in urban areas seem to be the apparent reasons for the dissatisfaction over conductor's behaviour on urban routes. This difference is the reason for the conflicts that occur between bus crews and passengers in urban buses. 


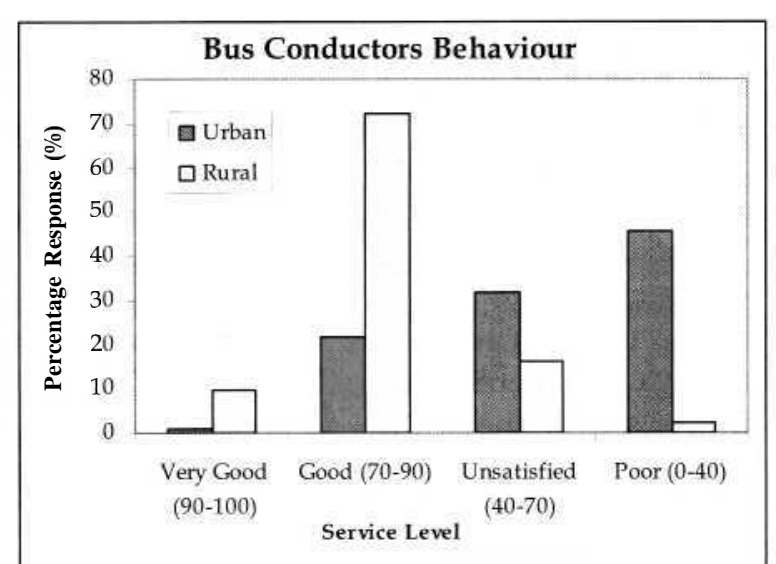

Figure 5: Passenger Responts Conductor's Behaviour

\section{Bus Driver's Behaviour}

The same trend as for bus conductor's behaviour is oọn in driver's behaviour (Figure 6). But this is cot as bad as conductor's behaviour. The rural passenger has accepted the driver's behaviour, while the urban passengers have rejected it. The same reasons as discussed previously for bus conductor's behaviour analysis can be attributed in this analysis as well.

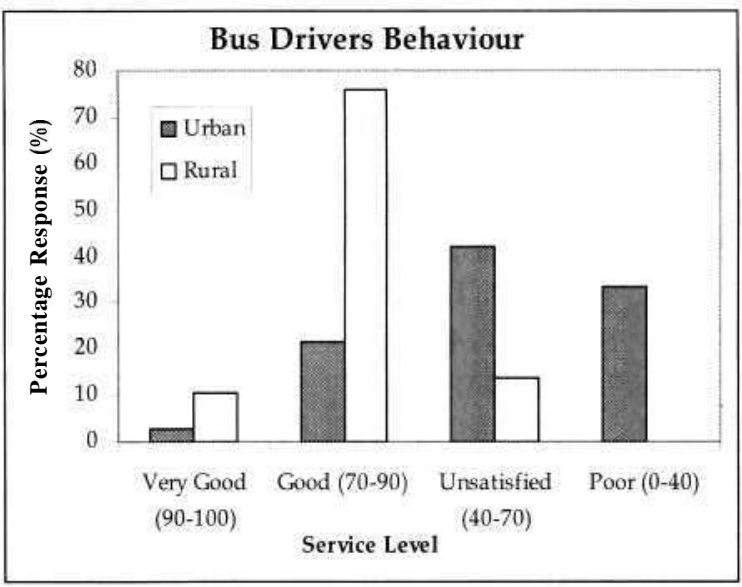

Figure 6: Passenger $\mathrm{R}=$ sponst om Trive $^{\prime}$ 's Behaviolir

\section{Issuing Tickets}

It is clearly shown in Figure 7 that this is a major issue in urban services compared toc $\mathrm{Vral}$ bus operations with more than $90 \%$ of passengers dissatisfied with the issuing (or in reality non-issue) of tickets. This is nnly $35 \%$ in rural areas. The average score on ticket issuing in urban areas is 37. This is the ser ond lowest in any discussed attribute of this $\mathrm{r} \epsilon \quad \mathrm{h}$. In the

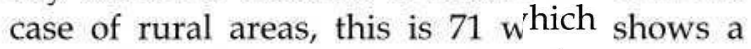
generally satisfactory level of service; One of the reasons for the difference in two situations could be the high market share of State owned buses in rural are o which grnerally issue tickets. Also the cverloading ir ${ }^{2}$ urkan areas encourage en $_{S}$ the somdustors not to issue $=$ kets. The user attitude in obtaining tickets wh № the rural passemger has a lower need for $\hat{c}$ „icket also may have led to thit different res. Onses from the passengers.

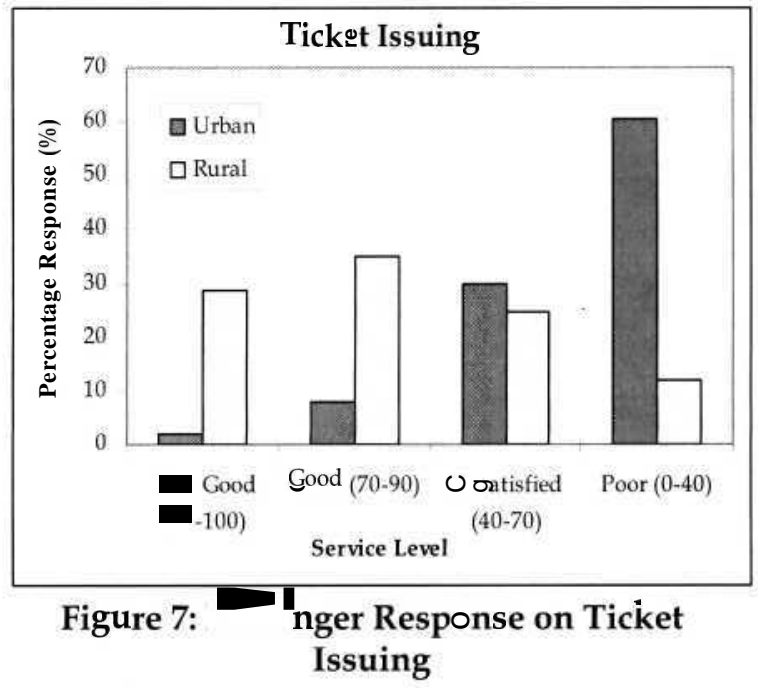

\section{Morning and Night Service}

Yet agein Figure 8 shows a typical inverse relatiorchip betwen urban and rural bus servi Us It show more than $87 \%$ of responses

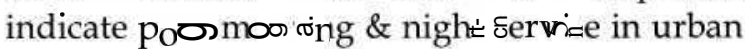
area wheseas only $30 \%$ of rural passengers complain. The severity level of service is indicated by average score of 45 and 76 in urban and rural areas respectively. The re $\boldsymbol{C}_{\mathrm{S}}$

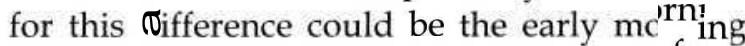
start of long distance $-s$ originated frc $n$ rural end and late hour's bus services provided from State owned buses. The need for Carly morning or late night services also may be higher in urban areas which have longer activity days. The analysis shows that there is a very high ree for a satisfactory early morning and late $v i \bar{c}$ ht $\wedge$ rvice in urban residential areas while in oral reas this is still at a satisfactory level.

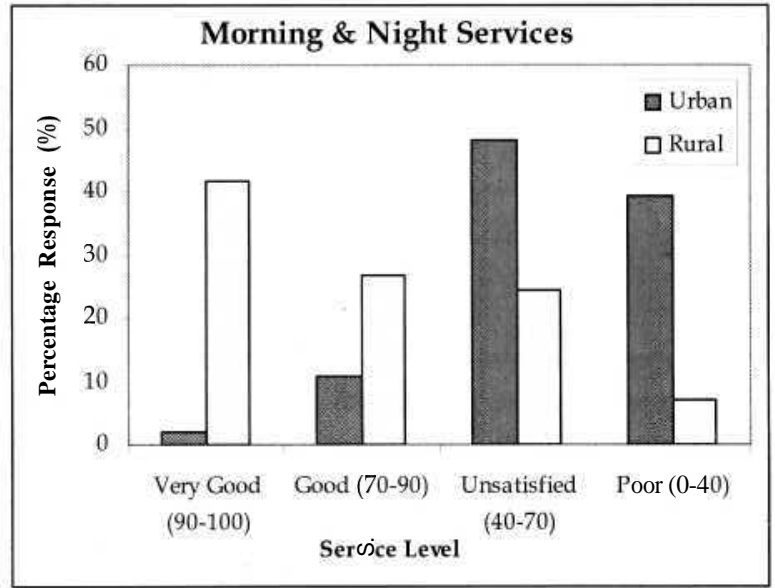

FiC Jre o: Passt gos Response om Mrsming \& Night \&trvices 
Condition of Bus Stops

Figure 9 shows an unsatisfact ${ }^{\text {ry }}$ level of the

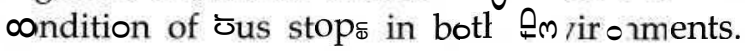
Passenger response confirms that their diss a isfaction levels are $77 \%$ and $88 \% 1 \mathrm{~m}$ orb amd rural situations respectively. The $\mathrm{h}_{\infty \mathrm{m}}$ the same aver age score (49) in both $=\Gamma \mathrm{s} \quad \mathrm{dij}^{\mathrm{c}}=\mathrm{ing}$ that the dissatisfaction is equally $= \pm$ im $\dot{0} 0 \mathrm{~h}$ areas.

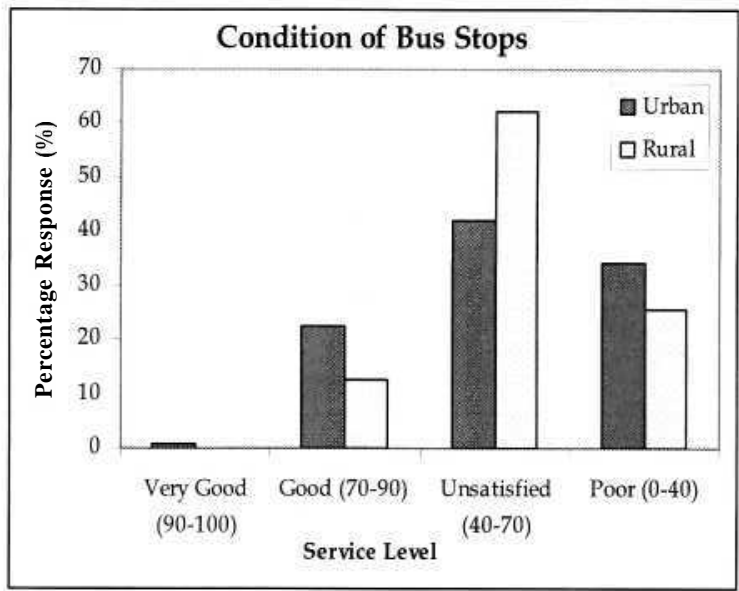

Figure 9: Pa 88 er Response on Condition of Bus Stops

\section{High" no Fare}

1ooo -ng to Fig cos 10 shown bellow, the

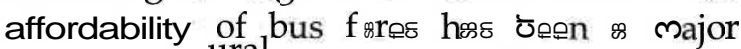
concern to $\bar{x}{ }^{\text {ural }}$ pessseng $\Theta \mathrm{w}$ ڤre passengers c:omplain less. Sevemty fivo percent $(75 \%)$ of only $42 \%$ of urban msponses say sе However, the average score of 73 ænd 60 from urbam $\circledast n \pi$ rural respomses indicote that this is not

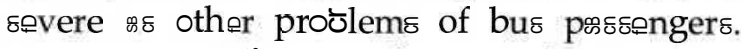

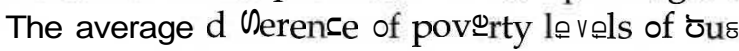
pæsธongers in two sontcxtร soems to ze the main reason for the two dissatisfaction @velc.

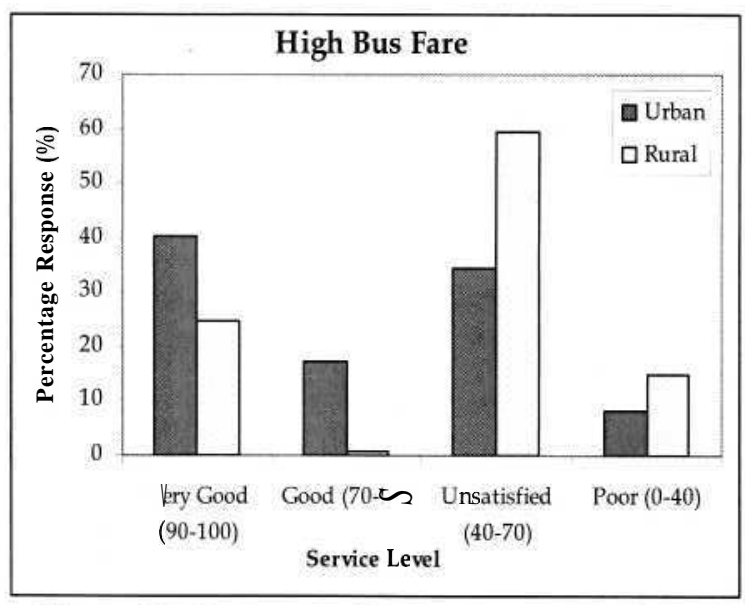

Figure 10: Pa $88 \cong n$

\section{Waiting Time}

The analysis of wait io for buses is given in the Figure 11. It shows tha : this problem is much severe for rurosl pissengers $(82 \%$ responses against) tha ${ }^{\mathrm{h}}$ urba $\mathrm{n}$ users $(42 \%)$. The main reason seoms to be the difference in despatching rate under different demand lev $\epsilon$ in the two environmsmts. In $\#_{\text {le }}$ rural conte $\mathrm{du}^{\mathrm{le}} \mathrm{t}_{\mathrm{b}}$ less competiton, buses tend to wa longer to fill them with passengers, while in urban areas due to sompeng services, this less grave problem is.

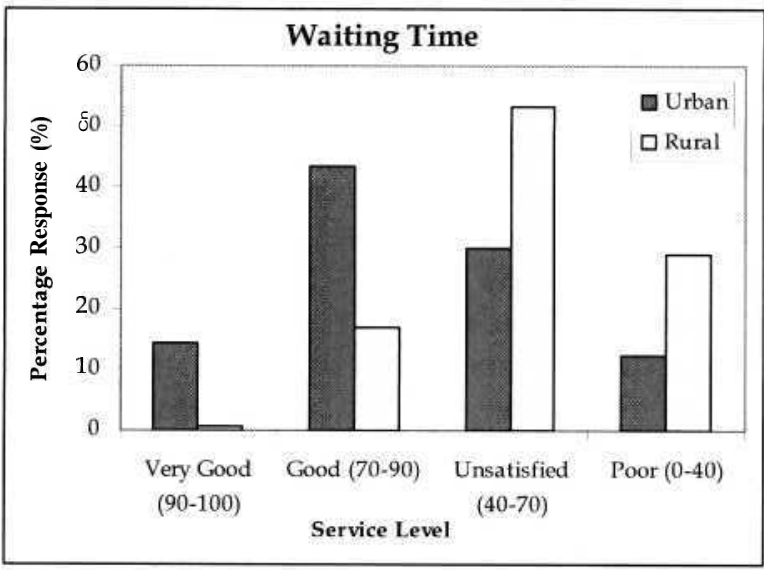

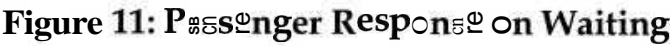
Time

\subsection{0 mmary of the Analysis of Household Eorveys}

According to the above analysis of the various æøp the most severe problem in both urban and rural bus transport is the overloading. Ticket issuing is the second most severe issue. Travel time and condition of bus stops have equal sevarity, followed by lack of morning and night services. Bus conductor's behaviour and waiting time have equal public complaint \&gainst them.

When we consider the issues separately according to the above analysis, problems in the urban bus transport system are much severe than in rural services. Most critical issues ih urban areas are overloading and non $i^{\text {ss }}$ ue of tickets. The most critical in rural areas are overloading, condition of bus stops and waiting time.

\subsection{Comparative Analysis of Bus Loadin T)ata}

The lomdint su mveys were conducted on Route nos. 342 d 433 which serve Moththegc dos 
(urban) area and Kudaligama (rural) area respectively.

The colleted data were analysed for both State owned buses and private operators. The number of passengers on board (loading data) have been considered as the demand at that time where as the number of seats in the bus as the supply.

The analysis of urban routes shows that the peak demand is between 7 and 9 AM where as the morning and evening peaks are less prominent in the rural areas. The demand in rural areas is rather consistent throughout the day. It was observed that there was a deficiency of the supply throughout the day in both urban and rural areas (Figure 12). This deficiency is much higher in the urban areas. The response from the passengers on overloading of buses has confirmed the severity of the situation (Figure 3). The flat nature of the supply graph indicates that there are deficiencies in scheduling of the supply and the lack of a demand based timetable. This is evident in the dissatisfaction shown by passengers towards travel time and waiting time shown in Figure 2 and Figure 11.

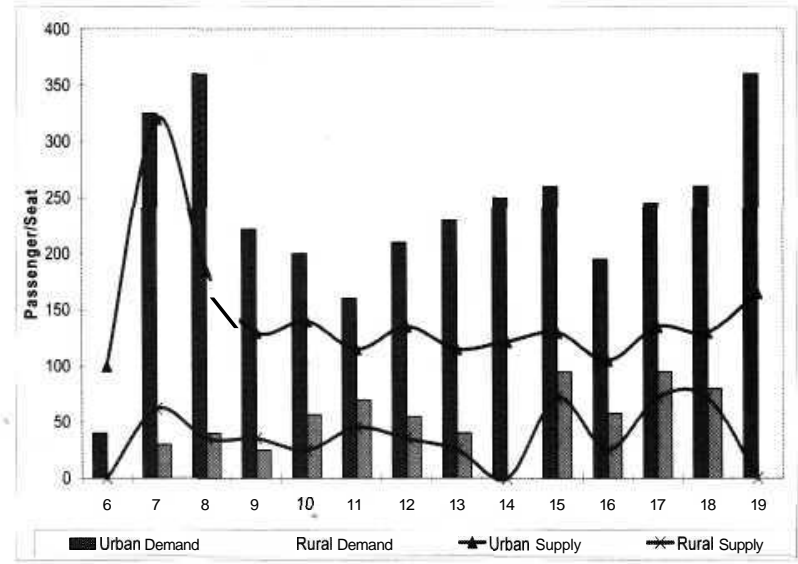

Figure 12: Demand and Supply Graph for Rural and Urban Bus Routes

As shown in Figure 12 it clearly shows the variation in the demand for the route as well as the deficiency in the supply which results in overloading.

\subsection{Comparative Analysis of Bus Travel Time Data}

The bus travel time surveys for the two bus routes in above rural and urban areas have been carried out separately.
The total length $(14.2 \mathrm{~km})$ of the rural road has been considered as two sections in which $7.6 \mathrm{~km}$ belongs to a main road where there is competition from other buses travelling to different destinations. The other section which is $6.6 \mathrm{~km}$ in length is purely serving the village. The travel time attributes of these two rural sections and the urban section are shown in Table 3.

Table 3: Travel Time, Delay and Speed Comparison

\begin{tabular}{|c|c|c|c|c|}
\hline \multirow[b]{2}{*}{ Details of Travel Attributes } & \multicolumn{3}{|c|}{ RuralRoad } & \multirow[b]{2}{*}{$\begin{array}{l}\text { Urban } \\
\text { Road }\end{array}$} \\
\hline & $\begin{array}{l}\text { Roult } \\
\text { Section }\end{array}$ & $\begin{array}{l}\text { Rond } \\
\text { Section }\end{array}$ & $\begin{array}{l}\text { Total } \\
\text { Iength }\end{array}$ & \\
\hline Number of Bus Trips in Data Sample & 9 & $\mathrm{~S}$ & 1.7 & 27 \\
\hline Length of Travel(km) & 7.6 & 6.6 & 14.2 & 4.5 \\
\hline \multicolumn{5}{|c|}{ Delay } \\
\hline Maximum Delay (min) & 29 & 33 & 37 & 14 \\
\hline Minimum Delay (min) & 4 & 2 & 2 & 3 \\
\hline Standard Deviation & 10 & 10 & 11 & 4 \\
\hline Coefficiento! Variance ( $\mathrm{CoV}) \%$ & 74 & 114 & 71 & 69 \\
\hline Average Total Delav [min] & 13 & 9 & 16 & 6 \\
\hline \multicolumn{5}{|c|}{ Travel Time } \\
\hline Travel Time (With Delay) [min] & 21 & 25 & 44 & 13 \\
\hline Travel Time (WithoutDelay) [min] & 16 & 20 & 35 & 10 \\
\hline \multicolumn{5}{|c|}{ Travel Speed } \\
\hline Travel Speed ( WithDelau: $[\mathrm{km} / \mathrm{hr}]$ & 22 & 17 & 20 & 22 \\
\hline Travel Speed r i vithoutDelay) [km/ hr] & 30 & 20 & 23 & 30 \\
\hline
\end{tabular}

Delay

The term delay referred to in this paper is the time duration where the bus remain at a bus halt over and above the time it takes for boarding and alighting of passengers. Average delays per kilometre are recorded as 75 seconds and 67 seconds per kilometre in urban and rural respectively. However, the initial delay at commencement of service in rural areas seems to be higher compared to the urban context. The high coefficient of variance $(\mathrm{CoV})$ of delay at rural road section also indicates the highly irregular travel behaviour in the rural section.

\section{Travel Speed}

The travel speed without delay is the actual average moving speed of the bus in a given road section. This has been calculated by dividing the total travel length by the summation of all travel times between two stops. This is high as $30 \mathrm{~km} / \mathrm{h}$ in urban areas which is an acceptable speed (Table 3). However, this is around $25 \mathrm{~km} / \mathrm{h}$ in rural route. It can be seen that this speed in the main road section is as high as $30 \mathrm{~km} / \mathrm{h}$ where as it is $20 \mathrm{~km} / \mathrm{h}$ in rural section. The higher speed on the main road section clearly indicates the competition by other buses which share the demand on the main road.

\section{Summary}

The first and second major issues of the public bus transport are overloading and travel time 
delay are clearly supported by the on-site observed data as discussed in section 6.3 and 6.4. There is a good relationship between the user comments and the observed data from loading and travel time surveys.

\section{Conclusion}

There is considerable dissatisfaction over the quality of bus services that are provided to both urban and rural areas as disclosed in this paper. The nature of the dissatisfaction vary between locations. The suburban area referred in this analysis, demands more qualitative bus transport and passengers are prepared to even pay higher fares. On the other hand the needs of the rural area are more in terms of the deficiency in quantity of transport. These passengers are conscious of costs and correspondingly make lesser demands on quality. However, both communities note that delays and overloading are a source for great irritation.

Delays appear to be in the form of lingering at bus halts where there is a higher likelihood of passenger collecting. Typically, junctions and bus stands are prime locations. Delays appear to be higher in shorter routes and routes where there is only one bus route service. On main roads served by a number of routes, delays are less. On some routes the total travel speed appears acceptable. However there is high speeds in certain sections and lingering in others. This driving pattern is highly unsatisfactory as it can lead to accidents on the one hand and unnecessary stress and waste of time on the part of the passengers.

The loading pattern of both bus routes clearly indicates the absence of a controlling timetable. A simple rule appears to govern the dispatching of buses. That is the buses are dispatched when all the seats are taken. In the peak period this appears a consistent rule. In off-peaks when buses are dispatched without seats filling up, operators delay at junctions in order to ensure higher load factors. There appears to be no real enforcement of time tables or over-loading by any of the regulatory bodies. As such, the passengers are at the mercy of the operator's patterns. The industry bears all the signs of a supply driven, unregulated industry, wherein the passenger exists only in order to ensure that the operators can maintain a business.
Since we cannot see any favourable improvements controlling agencies to address this situation for a long period of time. It is important to test a procedure to minimise the negative impact of some of the quality issues with passenger participation. This can be made successful by implementing passenger empowerment policies to allow public transport passengers to participate in the event within a legal framework. The analysis of this research paper can be used to understand the present problems and their magnitude when such policies are formulated.

\section{Acknowledgement}

The authors wish to acknowledge the use of data collected under the project "Partnerships in Transport Passenger Empowerment" funded by SEVANATHA - Urban Resource Centre. The completion of the data collection surveys was also made possible due to the support rendered by the community in the Mattegoda housing scheme and the village of Kudaligama who readily complied for the interviews.

\section{References}

1. Census of Population and Housing 2001, Colombo District Final Results, A publication by Department of Census and Statistics of Sri Lanka, 2001.

2. (http://en.wikipedia.org/wiki/Public_transp ort, last visited 22/04/2008).

3. Kaltheier. R. M., (2002), "Urban Transport and Poverty in Developing Countries", Analysis and Options for Transport Policy and Planning, Pp 25-33. ]

4. Kumarage A. S., (1990), "Intercity Travel Demand Modelling for Developing Countries", PhD Research, Calgary, Alberta, 1990

5. Kumarage A.S., (2001) "Fares Policy in Bus Transport in Sri Lanka", South Asian Forum for Infrastructure Regulations, Agra, India, October 2001.

6. Kumarage A.S., and Piyadasa J.D.A.I., (2003) "Formulation of a bus dispatching Policy to achieve simultaneous Economic and Financial Optimization of a Route:, ERU, Moratuwa, 2003.

7. Maunder, D A C and Mbara T. C., (1996). "Liberalization of urban public transport, Services, what are the implications?" Indian 
Journal of Transport Management, Vol. 20, No.2, 1996.

8. University of Southern California (2007), Bus Scheduling Algorithm Picks Up The Slack. Science Daily. Retrieved May 27, 2008,

9. Weerasinghe. S.C., (1990), Re-examination of Newel's Dispatching Policy and Extension to a Public Bus Route with Many to Many Time Varying Demand, $11^{\text {th }}$ International Symposium on Transportation and Traffic Theory, Tokyo, 1990

10. Weerasinghe. S.C. and Ghoneim. N.S (1981), Spacing of Bus Stops for Many to Many Travel Demand, Transportation Science, Vol. 15. No.3. August 1981. 